NUREG/CR-2457

PNL-4063

\title{
Radon Diffusion Through Uranium Mill Tailings and Cover Defects
}

Prepared by D. W. Mayer, D. A. Zimmerman

Pacific Northwest Laboratory

Operated by

Battelle Memorial Institute

Prepared for

U.S. Nuclear Regulatory

Commission 


\section{NOTICE}

This report was prepared as an account of work sponsored by an agency of the United States Government. Neither the United States Government nor any agency thereof, or any of their employees, makes any warranty, expressed or implied, or assumes any legal liability or responsibility for any third party's use, or the results of such use, of any information, apparatus product or process disclosed in this report, or represents that its use by such third party would not infringe privately owned rights.

Available from

GPO Sales Program

Division of Technical Information and Document Control

U. S. Nuclear Regulatory Commission Washington, D. C. 20555

Printed copy price: $\$ 2.75$

and

Nátional Technical Information Service

Springfield, Virginia 22161 
NUREG / CR-2457

PNL-4063

RU

\section{Radon Diffusion Through Uranium Mill Tailings and Cover Defects}

Manuscript Completed: November 1981

Date Published: December 1981

Prepared by

D. W. Mayer, D. A. Zimmerman

Pacific Northwest Laboratory

Richland, WA 99352

Prepared for

Division of Health, Siting and Waste Management

Office of Nuclear Regulatory Research

U.S. Nuclear Regulatory Commission

Washington, D.C. 20555

NRC FIN B2269 



\section{ABSTRACT}

Research was conducted at Pacific Northwest Laboratory to define the effects of cover defects on the emission of radon gas from covered uranium mill tailings piles. This report describes the results from the analysis of four geometrically simplified cover defects. 



\section{SUMMARY}

The purpose of the study was to determine how cover defects might affect the emission of radon gas from a covered tailings pile. The analysis was performed using the Pacific Northwest Laboratory (PNL) developed code, RADMD (RAdioactive Diffusion in Multipimensions). First, the code was verified against available one-dimensional steady-state solutions to the general radon diffusion equation. Next, the model was used to investigate the effects of four geometrically simplified cover defects. This analys is was performed in two dimensions by simulating a region perpendicular to the tailings and cover surfaces.

The results of this study show that cover defects can increase the average surface flux of radon gas 3 to 30 times the normal rate, depending on the severity of the cover defect. Cleariy, cover defects are an important consideration when designing covers to control radon emissions. The study also demonstrated that the code, RADMD, can match analytical solutions for bare and covered tailings to within $3 \%$. 

CONTENTS

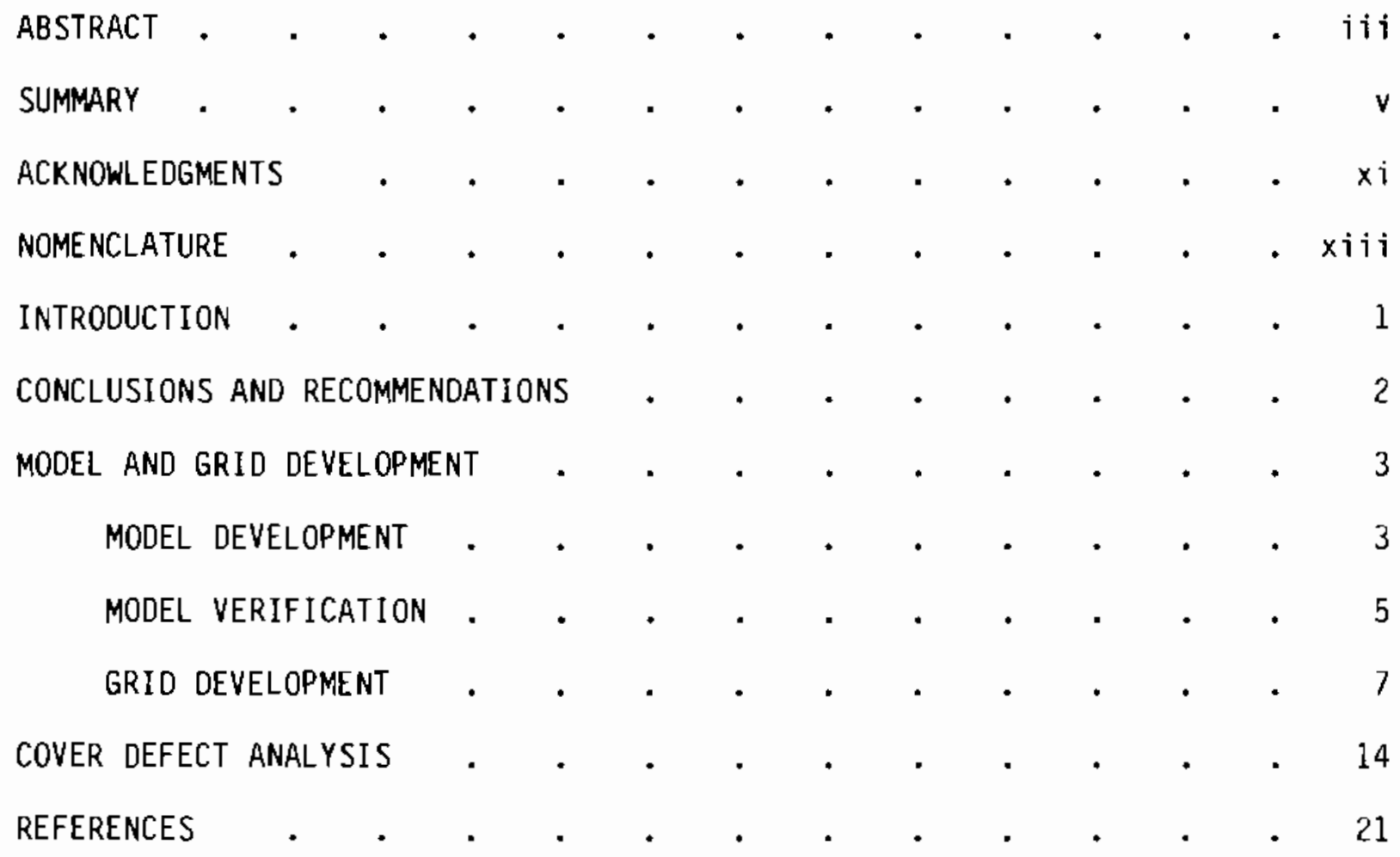

vi i 



\section{FIGURES}

1 Analytical Versus Numerical Solution, 600-cm-Thick Bare Tailings

2 Analytical Versus Numerical Solution, 100-cm Clay/Gravel Cover Over $600 \mathrm{~cm}$ of Tailings. . . . . . . . . y

3a Perforated Cover . . . . . . . . . . . 12

3b Deep Defect . . . . . . . . . . . . . 12

3c Small Defects . . . . . . . . . . . . . . 12

3d Wide Defect . . . . . . . . . . . . 12

4 Two-Dimensional Finite Difference Grid . . . . . . . 13

5a Surface Flux, Perforated Cover Case . . . . . . 16

5b Surface Flux, Deep Defect Case . . . . . . . 17

$5 c$ Surface Flux, Wide Defect Case . . . . . . . 18

5d Surface Flux, Small Defects Case . . . . . . . 19

6 Horizontal flux into the Perforation . . . . . . 20

$\underline{\text { TABLES }}$

1 Parameter Values . . . . . . . . . . 7

2 Surface Flux Results . . . . . . . . . . . 15 



\section{ACKNOWLEDGMENTS}

The authors wish to thank Mr. Wyatt B. Silker, a member of the Physical Sciences Department at Pacific Northwest Laboratory (PNL), for his guidance and support during the execution of this study. Dr. Charles T. Kincaid of the Water and Land Resources Department at PNL provided valuable assistance during the grid refinement phase of this study.

This work was funded by the U.S. Nuclear Regulatory Commission under FIN No. B-2269, "Attenuation of Radion Emissions from Uranium Mill Tailings." 



\section{NOMENCLATURE}

a Leading coefficient in the diffusion coefficient relationship (typica) value: 0.74 )

B The exponent in the diffusion coefficient relationship (typical value: 2.16)

C Concentration of radon gas, $\mathrm{pC} i-c \pi^{-3}$

c Specific heat, cal-g-1_o $\mathrm{C}^{-1}$

D Diffusion coefficient, $\mathrm{Cm}^{2}-\mathrm{hr}^{-1}$

E Emanating power (typical value: 0.2 )

G Heat generation rate per unit volume, cal- $\mathrm{s}^{-1}-\mathrm{Cm}^{-3}$

$J$ Diffusive fiux vector, $\mathrm{pC} i-\mathrm{Cm}^{2}-\mathrm{hr}^{-1}$

k Thermal conductivity, cal-s $\mathrm{s}^{-1} \mathrm{~cm}-\mathrm{I}_{-}^{\circ} \mathrm{C}-1$

$L \quad$ Thickness of a layer, $\mathrm{cm}$

P Volumetric material porosity or void fraction of the dry material

R Radium content, $\mathrm{pC} i-\mathrm{g}^{-1}$

$\ell \quad$ Diffusion relaxation path length, $\mathrm{cm}$

T Temperature, ${ }^{\circ} \mathrm{C}$

$\mathrm{t}$ Time, hr

$x$ Horizontal distance from the centerline, $\mathrm{cm}$

z Vertical elevation (typically referenced to bottom of tailings pile), $\mathrm{cm}$

a Tortuosity

$\overleftrightarrow{\nabla} \quad$ Del operator $\left(\bar{\nabla}=\hat{i} \frac{\partial}{\partial x}+\hat{j} \frac{\partial}{\partial y}+\hat{k} \frac{\partial}{\partial z}\right), \mathrm{cm}^{-1}$

$\lambda$ Decay constant, $\mathrm{hr}^{-1}$

p Density, $\mathrm{g}-\mathrm{cm} \mathrm{r}^{-3}$

$\theta \quad$ Volumetric moisture content 


\section{Subscrjpts}

a The property is for air

ave An average vaiue

BT A bare tailings value

e The property is an effective value

ND A value obtained with no cover defect

S A surface value

$t$ The property is for the tailings

\section{Superscripts}

- A reference value 


\section{INTRODUCTION}

Uranium mill tailings consist of the waste or refuse left after uranium processing. Typically, the tailings are slurried into large ponds called tailings piles that dry out over a period of time. Tailings contain significant quantities of radium and thus enit radon gas, a decay product of radium.

Concern has been expressed over the health and environmental aspects of open tailings piles. Exposure to radon gas and its daughters has been linked to Tung cancer. Therefore, studies have been initiated to investigate the feasibility and effectiveness of controlling radon emissions by covering the tailings pile with a variety of cover materials.

A major concern in designing a cover system is the effect that breaks or defects in the cover may have on the escape of radon gas. In response to this concern, Pacific Northwest Laboratory $(P N L){ }^{(a)}$ has contracted with the U.S. Nuclear Regulatory Commission to investigate the effects of cover defects on the diffusion of radon gas through uranium miil tailings covers. This study constitutes an assessment of the magnitude of the effect that four geometrically simplified cover defects would have on radon gas emission from a covered tailings pile. In addition to discussing RADMD, the multidimensional radon diffusion model that we used to analyze cover defects, this report verifies the model with two analytical solutions and gives our analysis of four idealized-cover-defect geometries.

(a) Operated by Battelle Memorial Institute 


\section{CONCLUSIONS AND RECOMMENDATIONS}

This study demonstrates that it is possible to model radon diffusion through bare tailings, covered tailings, and tailings covers having defects. The multidimensional radon diffusion model, RADMD, predicts the one-dimensional analytical solution for concentration to within $3 \%$ and predicts the surface flux to within $0.2 \%$.

The analysis of the four idealized cover defects shows that the total surface emission of radon gas will be increased by a factor of three for wide and small defects that penetrate $50 \%$ of the cover. A defect that penetrates $75 \%$ of the cover results in a six-fold increase of the surface radon flux, and a defect that perforates the cover increases the surface radon flux by a factor of 31 . These findings indicate that cover defects must be considered when covers are used to control radon gas emissions from uranium mill tailings.

The defect geometries are idealized, because the purpose of this study was to perform an initial assessment of cover defects. Future studies should take advantage of the multidimensional and variable geometry capabilities of RADMD to investigate cover defects more representative of the geometries of real defects. 


\section{MODEL AND GRID DEVELOPMENT}

This section discusses the computer model that simulates the diffusion of radioactive gases in porous media. In addition, the steps taken to develop a suitable finite difference grid for modeling the four cover defects are discussed.

\section{MODEL DEVELOPMENT}

The computer modej used to analyze the cover defects is based on the conservation of mass equation given by (Nelson et al. 1980)

$$
\frac{\partial}{\partial t}[(P-\theta) C]=\bar{\nabla} \cdot D_{e} \overline{\nabla C}-(P-\theta) \lambda C+R_{p_{b}} \lambda E
$$

where,

$(P-\theta)$ is the gas filled pore space in the porous material,

$P$ is the material porosity or void fraction of dry soit on a volume basis,

$\theta$ is the moisture content on a volume basis,

$C$ is the pore (gas filled) concentration of radon (typical units: oc $\left.\mathrm{i}-\mathrm{Cm}^{-3}\right)$,

$D_{e}$ is the effective diffusion coefficient (typical units: $\left.c m^{2}-h r^{-1}\right)$

$\lambda$ is the decay constant for radon (typical units: $h r^{-1}$ ),

$R$ is the radium $\left({ }^{226} \mathrm{Ra}\right)$ content in the porous material (typical units: $p\left(i-g^{-1}\right)$,

$E$ is the emanating power of the materiai, which is slightly dependent upon the moisture content, particularly at very low moisture contents (see Tanner 1974).

The left term in Equation (1) accounts for the change in radon gas concentration (in the gas-filled pores) with time. The second term takes into 
account the change in radon concentration due to diffusion. The third term is a sink term that accounts for loss of radon by radioactive decay, and the final term is a source term that accounts for the generation of radon by radioactive decay of radium.

The diffusive flux vector, $\bar{J}$, can be defined based on Fick's law as follows:

$$
J=-D e^{\bar{\nabla} C}
$$

A relationship describing the dependence of $D_{e}$ on the air-filled pore space has been developed by Nelson et al. (1980) and is expressed by

$$
D_{e}=a 0_{a}^{0}(P-\theta)^{B}+D_{w}^{0} \alpha \theta
$$

where,

a is an empirically determined coefficient (typicai value: 0.740 ), $D_{a}^{0}$ is the radon diffusivity in air (typical value: $360 \mathrm{~cm}^{2}-\mathrm{hr}^{-1}$ ), $B$ is an empirically determined coefficient (typical value: 2.16), $D_{w}^{\circ}$ is the radon diffusivity in water (typical value: $0.036 \mathrm{~cm}^{2}-\mathrm{hr}^{-1}$ ) $a$ is the tortuosity (typical value: 0.66 ).

Equations (1), (2) and (3) are the basic equations used to modei transient, multidimensional radon diffusion through tailings ano cover layers.

To solve this system of equations, we have taken advantage of the mathematical similarity between heat conduction and gaseous diffusion processes. The equations describing each process are identical except for the decay term arising in the radon diffusion equation. For purposes of comparison, the heat conduction equation (excluding convection) is given by

$$
\rho c \frac{\partial T}{\partial t}=\bar{\nabla} \cdot k \bar{\nabla} T+G
$$


where,
$\rho$ is mass density,
$C$ is specific heat,
$\mathrm{T}$ is temperature,
$t$ is time,
$k$ is thermal conductivity, and
$G$ is heat generation per unit volume.

The general radon diffusion equation can be rewritten if it is assumed that the gas filled porosity, $P-\theta$, is constant or nearly constant (at least during a given time step). The equation would be

$$
(P-\theta) \frac{\partial C}{\partial t}=\bar{\nabla} \cdot D e^{\bar{\nabla} C}-(P-\theta) \lambda C+R \rho_{b} \lambda E
$$

Equation (5) is identical to Equation (4) with the addition of the decay term, $-(P-\theta) \lambda C$. The source term, $R p_{b} \lambda E$, is analagous to the neat generation rate, $G$.

The multidimensional heat transfer code, TRUMP (Edwards 1972), has been developed to solve Equation (4) using integrated finite difference techniques. Modification of the basic solution scheme employed by TRUMP has led to a new code known as RADMD (RAdioactive Diffusion in Multioimensions) (Mayer et al. 1981). RADMD can be used to solve radon diffusion problems in one, two, and three dimensions. These problems can be solved in either Cartesian, cylindrical, or spherical coordinate systems, as appropriate, for a given problem. Since the numerical formulation is based on an integrated finite difference representation of Equation (5), irregular grids can be used (i.e., the mode] is not limited to the more traditional rectangular finite difference cells).

\section{MOOEL VERIFICATION}

Before performing the simulations of the cover defects, we verified the model's ability to simulate radon diffusion. This was accomplished by performing two simulations and comparing the results against available steady-state, 
one-dimensional, analytical solutions to Equation (1). The two cases simulated were for the diffusion of radon through bare tailings, and for diffusion of radon through tailings isolated by a single cover. Analytical solutions for the bare tailings flux and the concentration profile have been reported previously (Mayer et al. 1981).

The first problem considered a bare tailings pile with the tailings layer characteristics shown in Table 1. The diffusion coefficient for the layer was computed using Equation (3). The boundary conditions imposed are a zero radon concentration at the surface and zero radon flux at the bottom of the tailings. The finite difference grid used to simulate this problem consisted of a column of 48 cells, each of them $12.5-\mathrm{cm}$ thick. The nodes are cell centered with an additional node placed at the surface of the tailings.

The concentration profile predicted by RADMD is shown in Figure 1 ; the corresponding analytical solution has aiso been plotted. It is obvious that the numerical results are in excellent agreement with the analytical solution. The predicted concentrations are within $3 \%$ of the analytical values. The predicted bare tailings flux is $308.19 \mathrm{pCi}-\mathrm{cm}^{-2}-\mathrm{hr}^{-1}$, matching the analytic solution to within $0.2 \%$.

The next case considered is the diffusion of radon in a two-layer system. The system consists of a 600-cm-thick tailings pile covered with a 100-cm clayl gravel mix. The layer characteristics are listed in Table 1. The boundary conditions were the same as for the previous simulation. The finite difference grid is the grid that was developed for the cover defect simulations (discussed in more detail in the following section). Figure 2 is a plot of the predicted concentration profile and the analytical concentration profile. Again, the results are in excellent agreement. The predicted surface flux for this case is $2.29 \mathrm{pCi}-\mathrm{cm}^{-2}-\mathrm{hr}^{-1}$, which is within $0.2 \%$ of the analytical value.

These results clearly demonstrate the model's capability to simulate radon diffusion in tailings and covered tailings piles. 
TABLE 1. Parameter Values

\begin{tabular}{|c|c|c|c|}
\hline Parameter & Air & Cover Layer & Tailings Layer \\
\hline$P, \mathrm{~cm}^{3}-\mathrm{cm}^{-3}$ & 1 & 0.26 & 0.55 \\
\hline$\theta, \mathrm{cm}^{3}-\mathrm{cm}^{-3}$ & 0 & 0.20 & 0.19 \\
\hline$\rho, \mathrm{g}-\mathrm{cm}^{-3}$ & NR & 2.00 & 1.23 \\
\hline$D_{e}, \mathrm{~cm}^{2}-\mathrm{hr}^{-1}$ & 360 & 0.6156 & 29.34 \\
\hline $\mathrm{E}$, & 0 & 0 & 0.2 \\
\hline$R, p C i-g^{-1}$ & 0 & 0 & 1600 \\
\hline$\lambda, \mathrm{hr}^{-1}$ & $7.5546 \cdot 10^{-3}$ & $7.5546 \cdot 10^{-3}$ & $7.5546 \cdot 10^{-3}$ \\
\hline
\end{tabular}

\section{GRID DEVELOPMENT}

The first step in designing a grid is to determine the degree of refinement necessary to simulate the problem and obtain an accurate solution. A grid constructed with too coarse a mesh will yield inaccurate results; a mesh that is too fine significantly increases computer costs. Mesh resolution is most important near areas of nonuniform geometry, where boundary conditions exist, or where material properties change. By comparing the numerical results with an analytical solution, adjustments can be made to the cell spacing to obtain a solution with the desired accuracy. An examination of the predicted concentration profile could also be used for this purpose. The profile should approximate a smooth curve with no significant discontinuities. Discontinuities in the predicted concentration profile result in inaccurate flux predictions since the flux is based on the concentration gradient.

The system analyzed for this study consists of a 600-cm-thick uranium mill tailings layer covered with a $100-\mathrm{cm}-$ thick layer of clay/gravel mix. The characteristics for these layers have been listed in Table 1. The first step in the grid development was to perform several simulations of the system in one dimension. Several discretization schemes were employed using cell thicknesses of 1,5 , and $10 \mathrm{~cm}$ near the surface and material interface boundaries. The model results were compared with one-dimensional analytic solutions (Mayer et al. 1981) for the surface flux, and the flux at the cover-tailings 


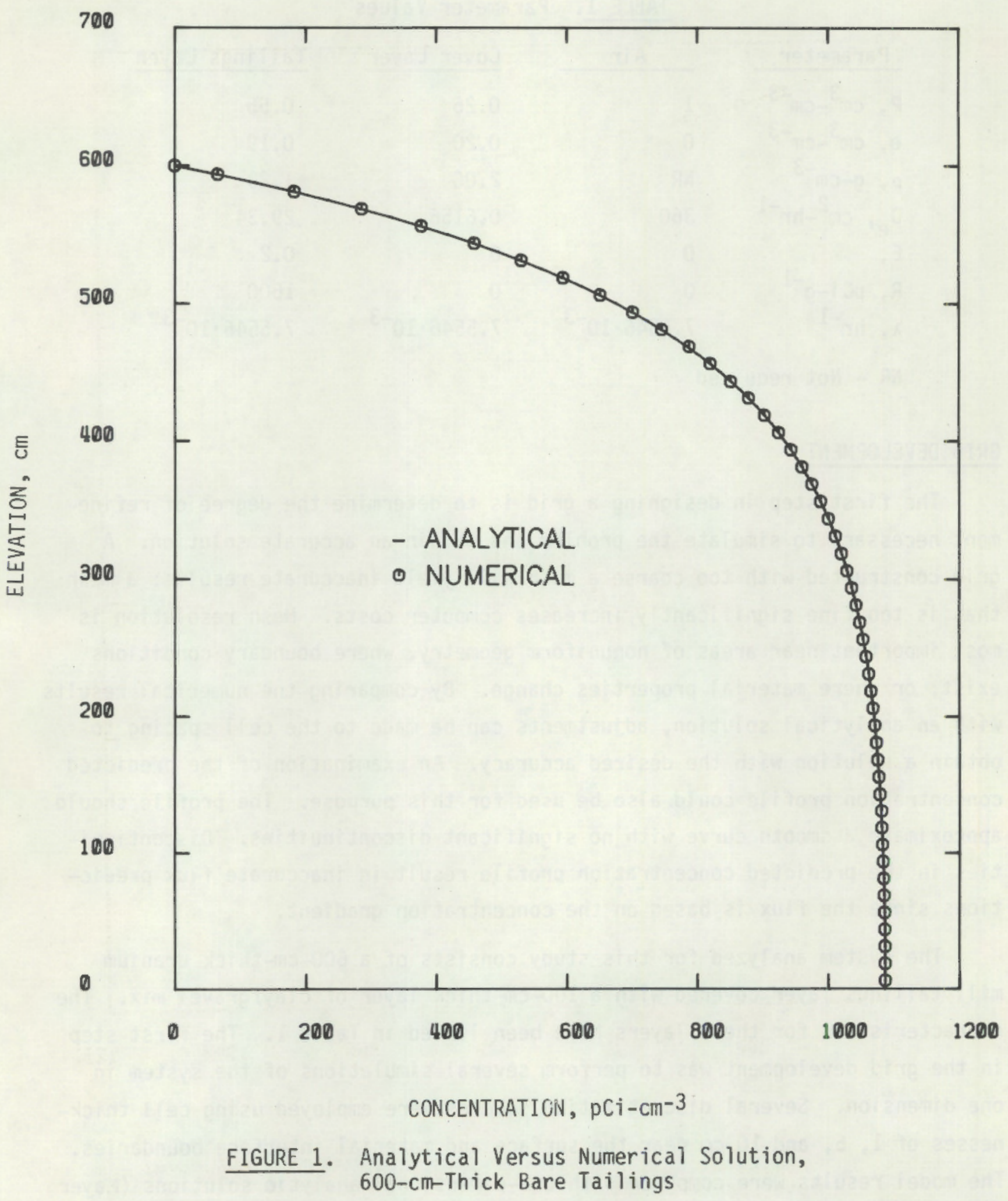




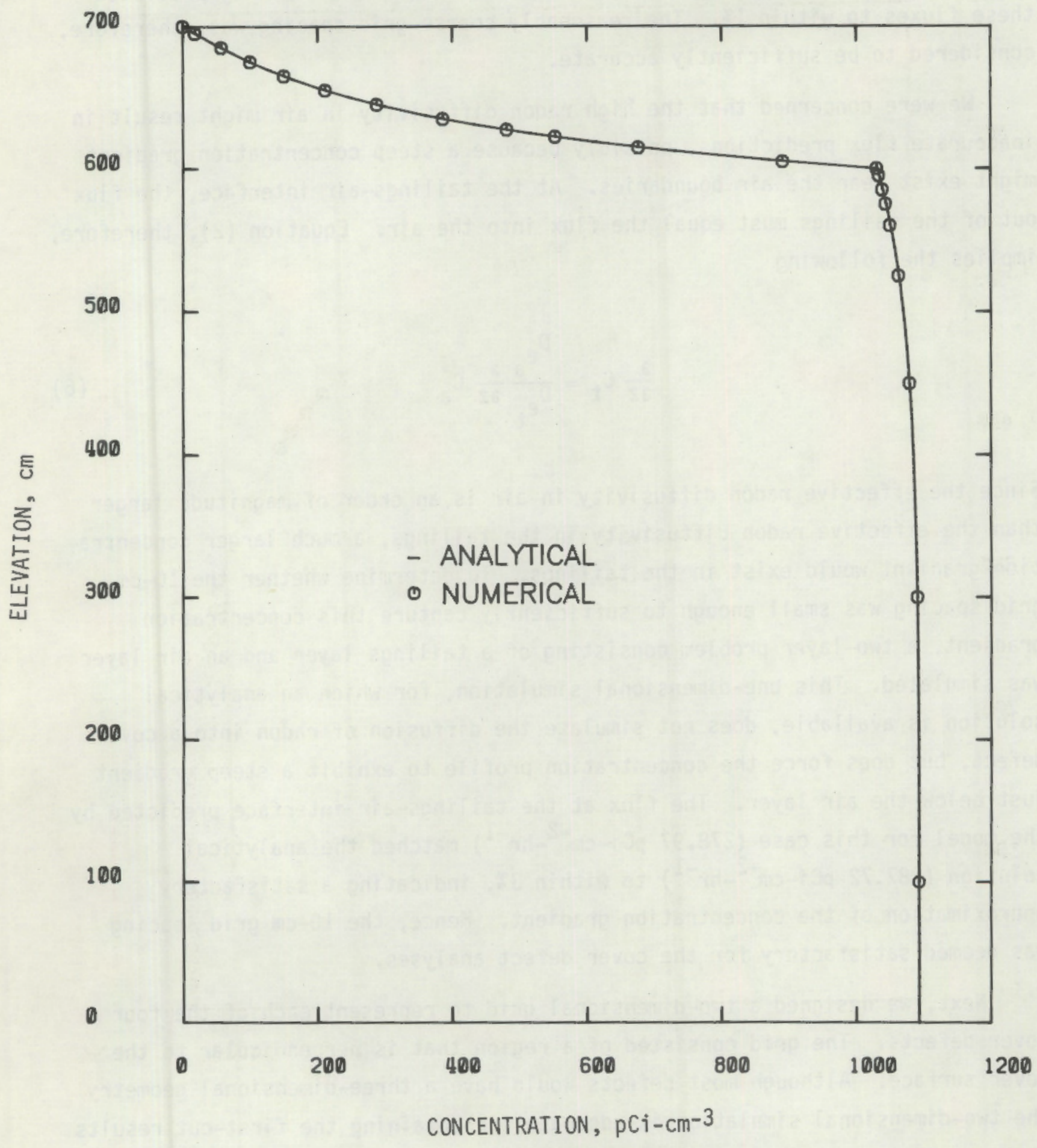

FIGURE 2. Analytical Versus Numerical Solution, 100-cm Clay/Gravel Cover Over $600 \mathrm{~cm}$ of Tailings 
interface. The model results for the grid with the 10- $\mathrm{cm}$ spacing predicted these fluxes to within $1 \%$. The reasonably coarse grid spacing was, therefore, considered to be sufficiently accurate.

We were concerned that the high radon diffusivity in air might result in inaccurate flux predictions, possibly because a steep concentration gradient might exist near the air boundaries. At the tailings-air interface, the flux out of the tailings must equal the flux into the air. Equation (2), therefore, implies the following

$$
\frac{\partial}{\partial z} C_{t}=\frac{D_{e_{a}}}{D_{e_{t}}} \frac{\partial}{\partial z} C_{a}
$$

Since the effective radon diffusivity in air is an order of magnitude larger than the effective radon diffusivity in the tailings, a much larger concentration gradient would exist in the tailings. To determine whether the 10-cm grid spacing was small enough to sufficiently capture this concentration gradient, a two-layer problem consisting of a tailings layer and an air layer was simulated. This one-dimensional simulation, for which an analytical solution is available, does not simulate the diffusion of radon into a cover defect, but does force the concentration profile to exhibit a steep gradient just below the air layer. The flux at the tailings-air interface predicted by the model for this case $\left(278.97 \mathrm{pCi}-\mathrm{cm}^{-2}-\mathrm{hr}^{-1}\right)$ matched the analytical solution ( $287.72 \mathrm{pCi}-\mathrm{cm}^{-2}-\mathrm{hr}^{-1}$ ) to within $3 \%$, indicating a satisfactory approximation of the concentration gradient. Hence, the 10-cm grid spacing was deemed satisfactory for the cover defect analyses.

Next, we designed a two-dimensional grid to represent each of the four cover defects. The grid consisted of a region that is perpendicular to the cover surface. Although most defects would have a three-dimensional geometry the two-dimensional simulation is adequate for obtaining the first-cut results that are desired. The cases considered are: 
- a perforated cover,

- a deep defect,

- a wide defect, and

- three small defects.

The total defect cross-sectional area was held constant at $150 \mathrm{~cm}^{2}$ in each of the four cases for comparison purposes. These different cases are illustrated in Figures $3 \mathrm{a}$ through $3 \mathrm{~d}$. We decided to use one grid that could adequately represent all four cases instead of four separate grids. This decision was made primarily to eliminate the potential for grid description error, since the geometric input data requirements for each grid are quite lengthy and tedious. Additional computational savings were obtained by noting that the centerlines in Figure 3 (as well as the left and right boundaries) represent planes of symmetry. Thus, it is only necessary to model one-haif of each case, thereby significantly reducing the number of finite difference cells. The resulting mesh, used to represent the left half of each case, is illustrated in Figure 4.

Note that the cell widths are much smaller than the cell thicknesses (Figure 4 is not drawn to scale). The horizontal cell spacing was determined by two considerations: 1) the necessity of having cells along the boundaries of each of the defects, and 2) a consequence of the integrated finite difference method, which restricts the percentage change in volume of adjacent cells. As a result, the horizontal grid spacing is much finer than the vertical spacing. The finer spacing in the horizontal direction should achieve sufficient accuracy, because the horizontal fluxes are expected to generally be smaller than the vertical fluxes. If larger fluxes are obtained, the finer mesh should still be sufficiently accurate.

To ensure that the grid was described accurately, the two-layer case (discussed under model verification) was performed using the two-dimensional grid. The resulting concentration profile (Figure 2) was discussed previously. The excellent agreement between the analytical and numerical solution indicate the accuracy of the grid description. 


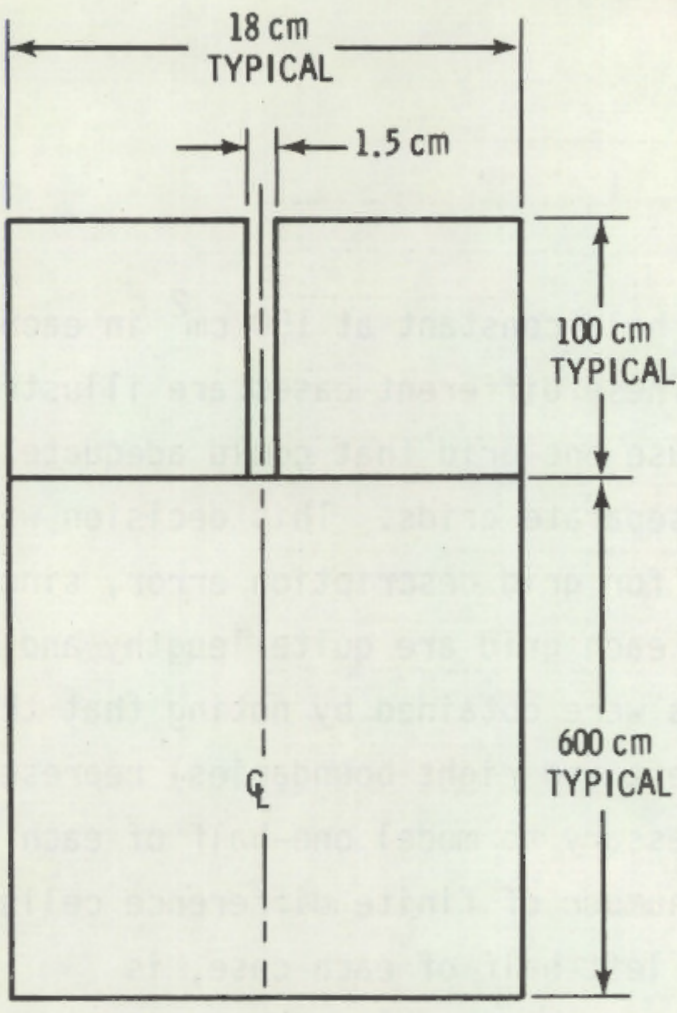

FIGURE 3a. Perforated Cover

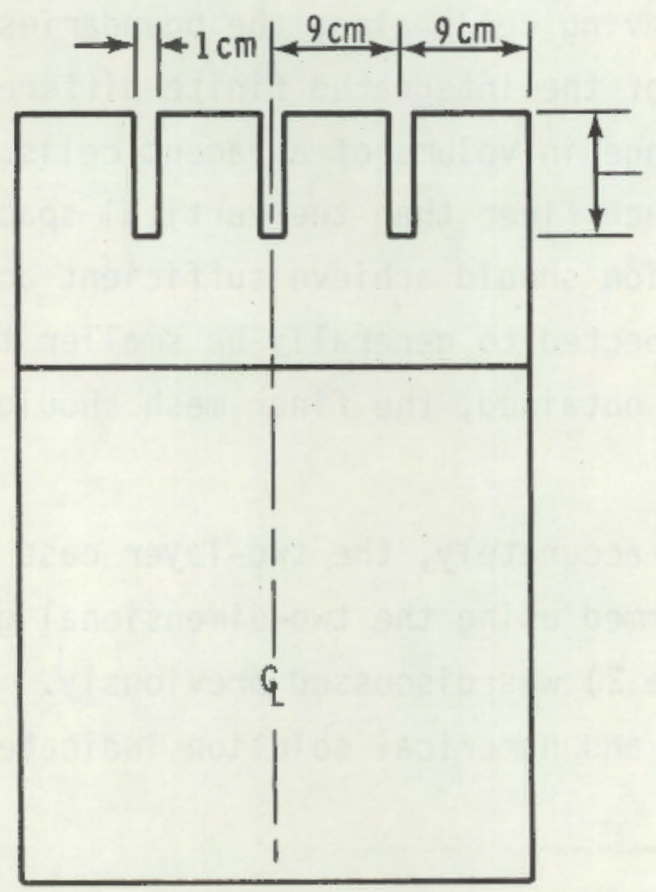

FIGURE 3c. Small Defects

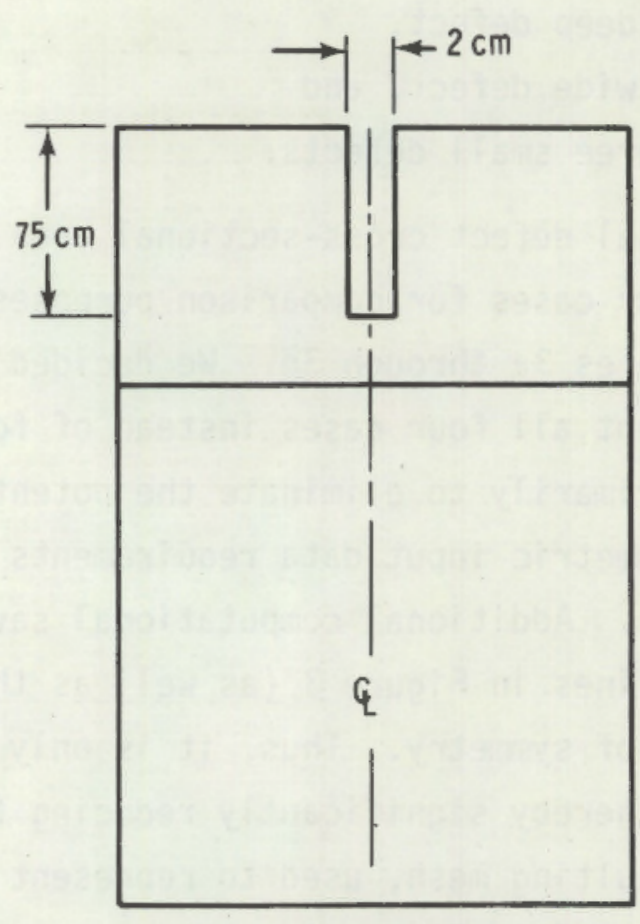

FIGURE 3b. Deep Defect

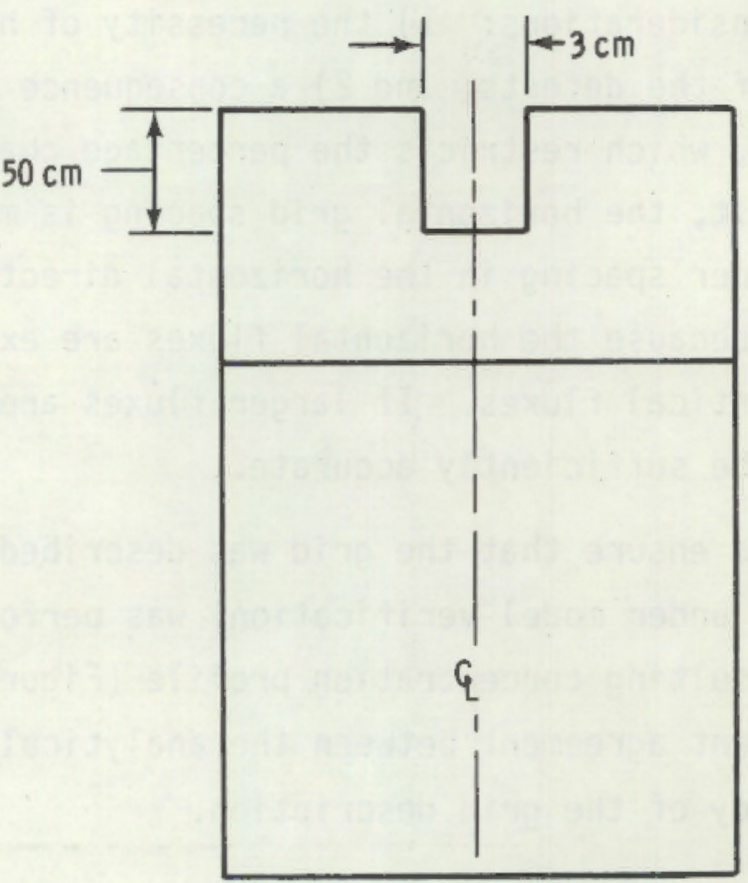

FIGURE 3d. Wide Defect 


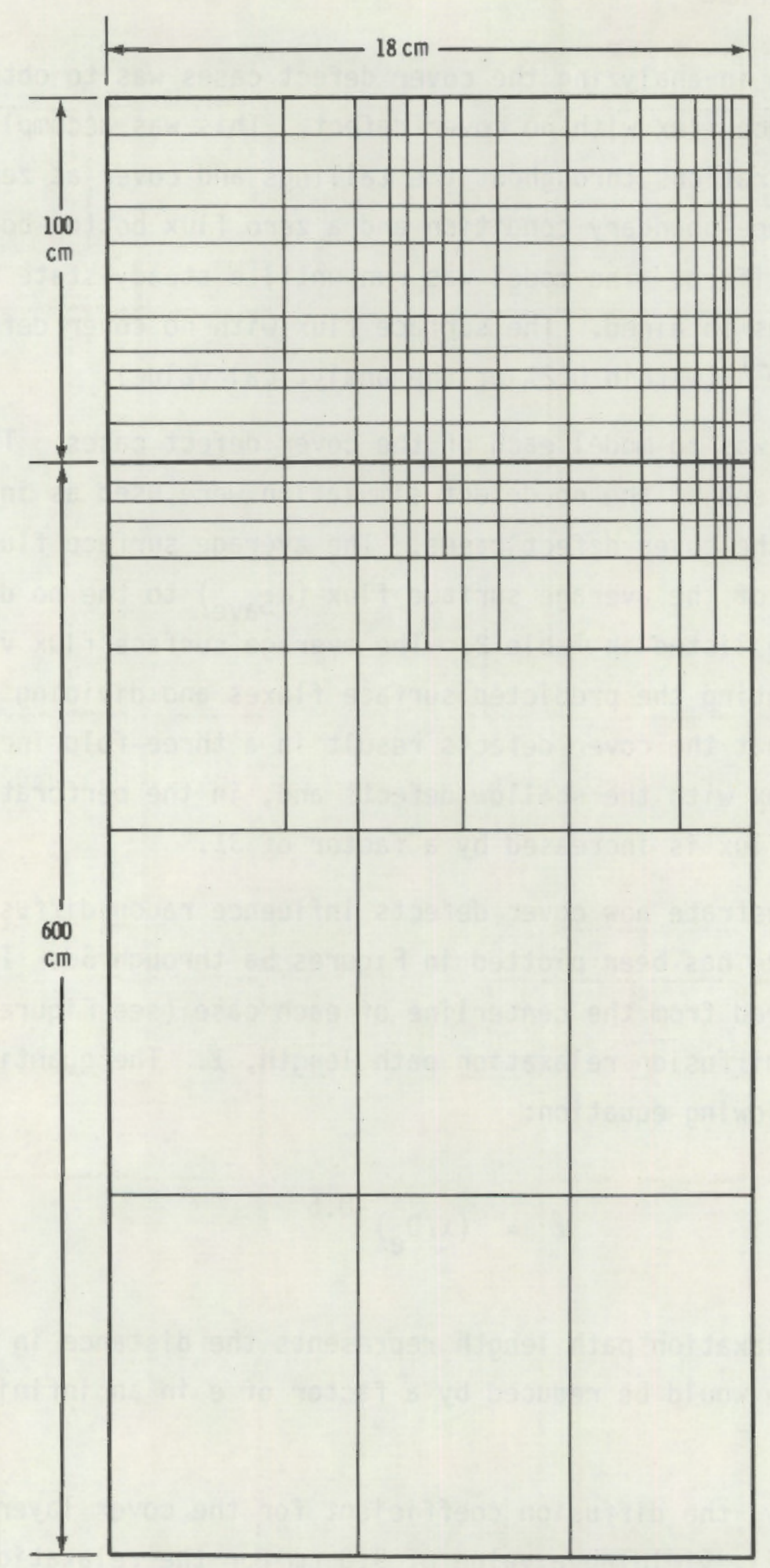

FIGURE 4. Two-Dimensional Finite Difference Grid (not drawn to scale) 


\section{COVER DEFECT ANALYSIS}

The first step in analyzing the cover defect cases was to obtain the value for the surface flux with no cover defect. This was accomplished by setting the concentrations throughout the tailings and cover at zero. A zero concentration surface-boundary condition and a zero flux bottom-boundary condition were specified. The model was run until a steady-state value for the surface flux was obtained. The surface flux with no cover defect, $\bar{J}_{N D}$, is $2.29 \mathrm{pCi}-\mathrm{Cm}^{-2}-\mathrm{hr}^{-1}$ (within $0.2 \%$ of the analytical vaiue).

The next step was to model each of the cover defect cases. The concentration values at the end of the no defect simulation were used as initial conditions for each of the cover defect cases. The average surface flux for each case and the ratio of the average surface flux $\left(\bar{J}_{S_{a v e}}\right)$ to the no defect surface flux $\left(\bar{J}_{N D}\right)$ are listed in Table 2. The average surface flux values were obtained by integrating the predicted surface fluxes and dividing by the surface area. Note that the cover defects result in a three-fold increase in the average surface flux with the shallow defects and, in the perforated cover case, the surface flux is increased by a factor of 31 .

To better illustrate how cover defects influence radon diffusion, the flux at each surface node has been plotted in Figures $5 a$ through $5 d$. The horizontal distance, $X$, measured from the centerline of each case (see Figure 3 ) has been normalized by the diffusion relaxation path length, $\ell$. The quantity, $\ell$, is defined by the following equation:

$$
\ell=\left(\lambda / D_{e}\right)^{-0.5}
$$

Physically, the relaxation path length represents the distance in which the radon concentration would be reduced by a factor of $e$ in an infinitely thick cover.

For this study, the diffusion coefficient for the cover layer has been used in Equation (7), yielding a value of $9.0 \mathrm{~cm}$ for the relaxation path 
TABLE 2. Surface Flux Results

\begin{tabular}{|c|c|c|}
\hline Case & $\left(p C i-c m^{-2}-h r^{-1}\right)$ & Save ND \\
\hline No Defect & 2.29 & 1.0 \\
\hline Perforated Cover & 71.5 & 31.0 \\
\hline Deep Defect & 13.7 & 6.0 \\
\hline Wide Defect & 6.83 & 3.0 \\
\hline Small Defects & 7.59 & 3.3 \\
\hline
\end{tabular}

length. For convenience, the surface flux with no defect is shown on each plot and the average surface flux with the cover defect is indicated.

Note that the surface flux over the solid portion of the cover for the cover defect cases is less than the no defect surface flux value except for the perforated cover case. The elevated surface flux for the perforated cover case occurs because of the high radon concentration in the defect near the tailings surface. The elevated concentration of radon in the perforation results in diffusion back into the cover. This phenomenon is illustrated by the flux profile along the left side of the perforation that is plotted in Figure 6 . Notice that, near the bottom of the perforation, there exists a large radon gas flux into the perforation. At $\sim 25 \mathrm{~cm}$ above the tailings, the direction of the flux reverses due to the increased concentration in the perforation. 


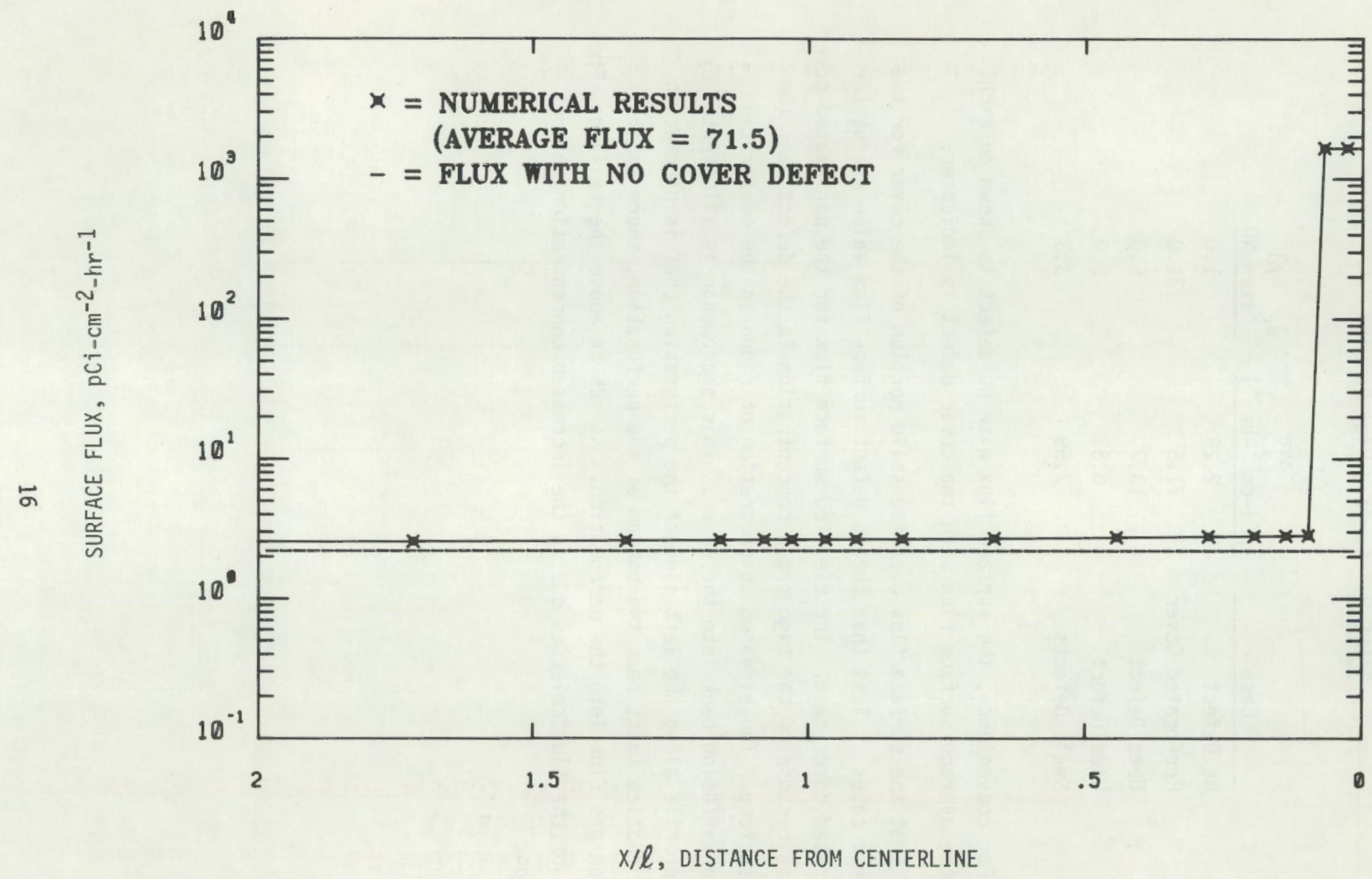

FIGURE 5a. Surface Flux, Perforated Cover Case 


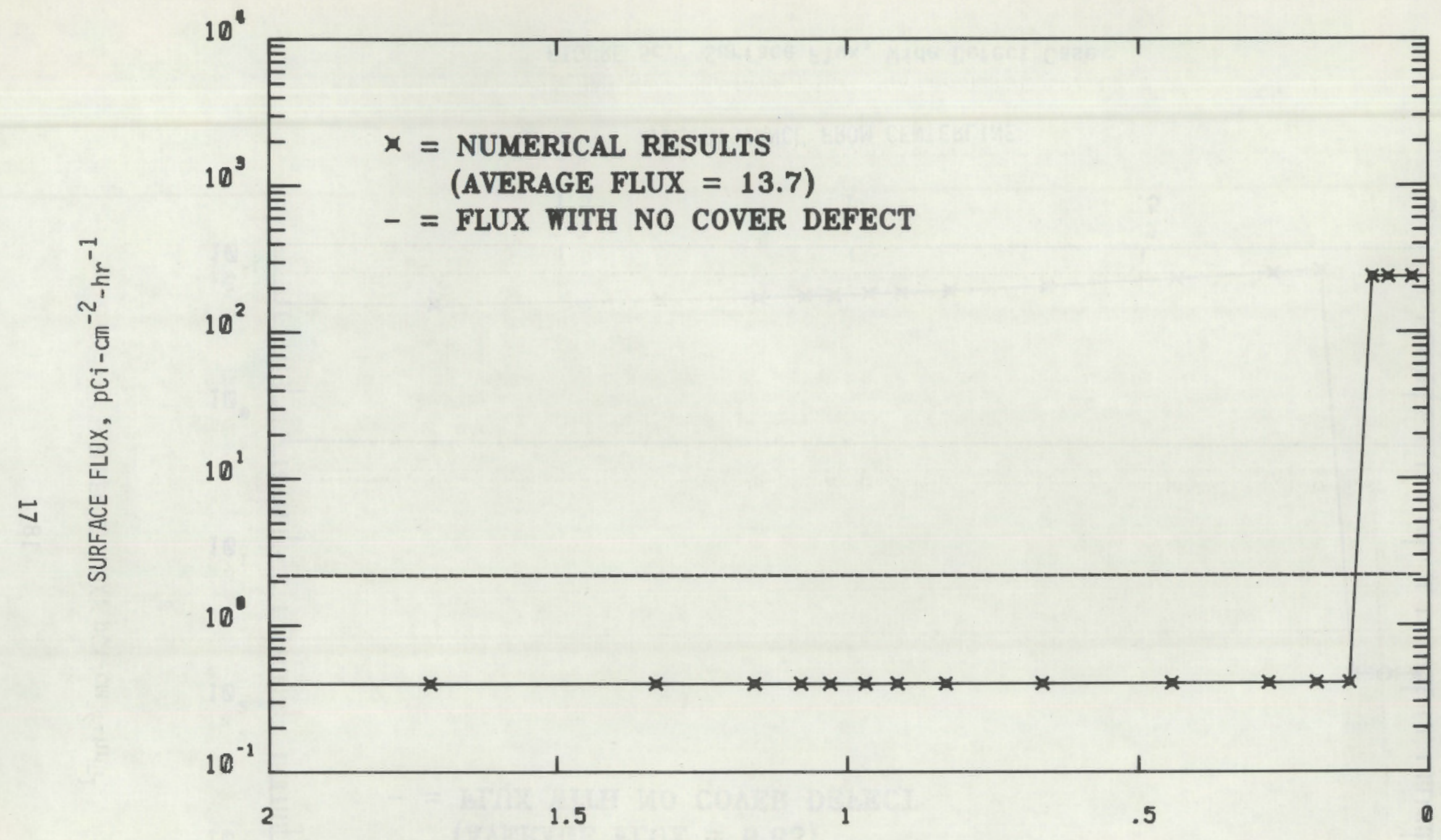

$x / \ell$, DISTANCE. FROM CENTERLINE

FIGURE 5b. Surface Flux, Deep Defect Case 


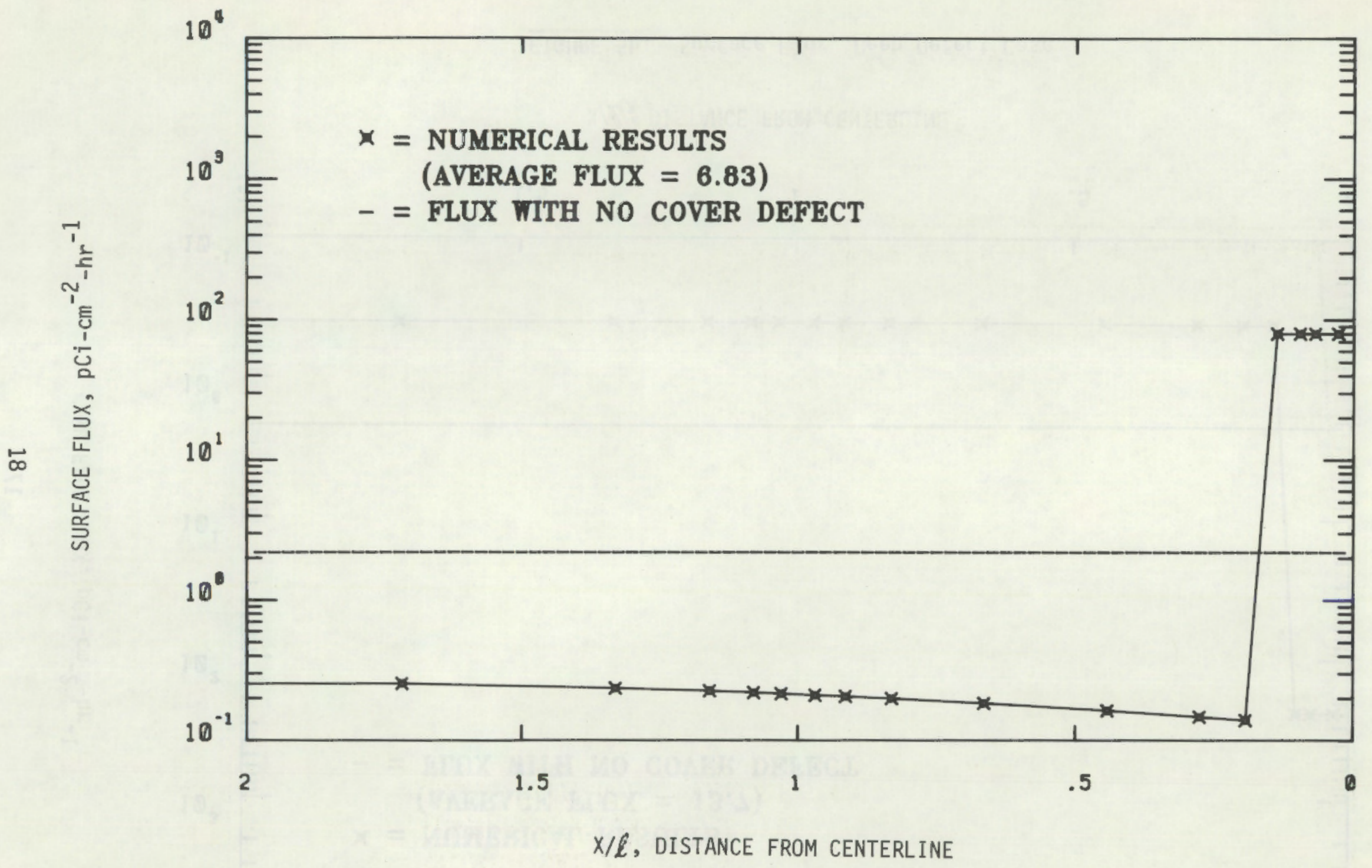

FIGURE 5c. Surface Flux, Wide Defect Case 


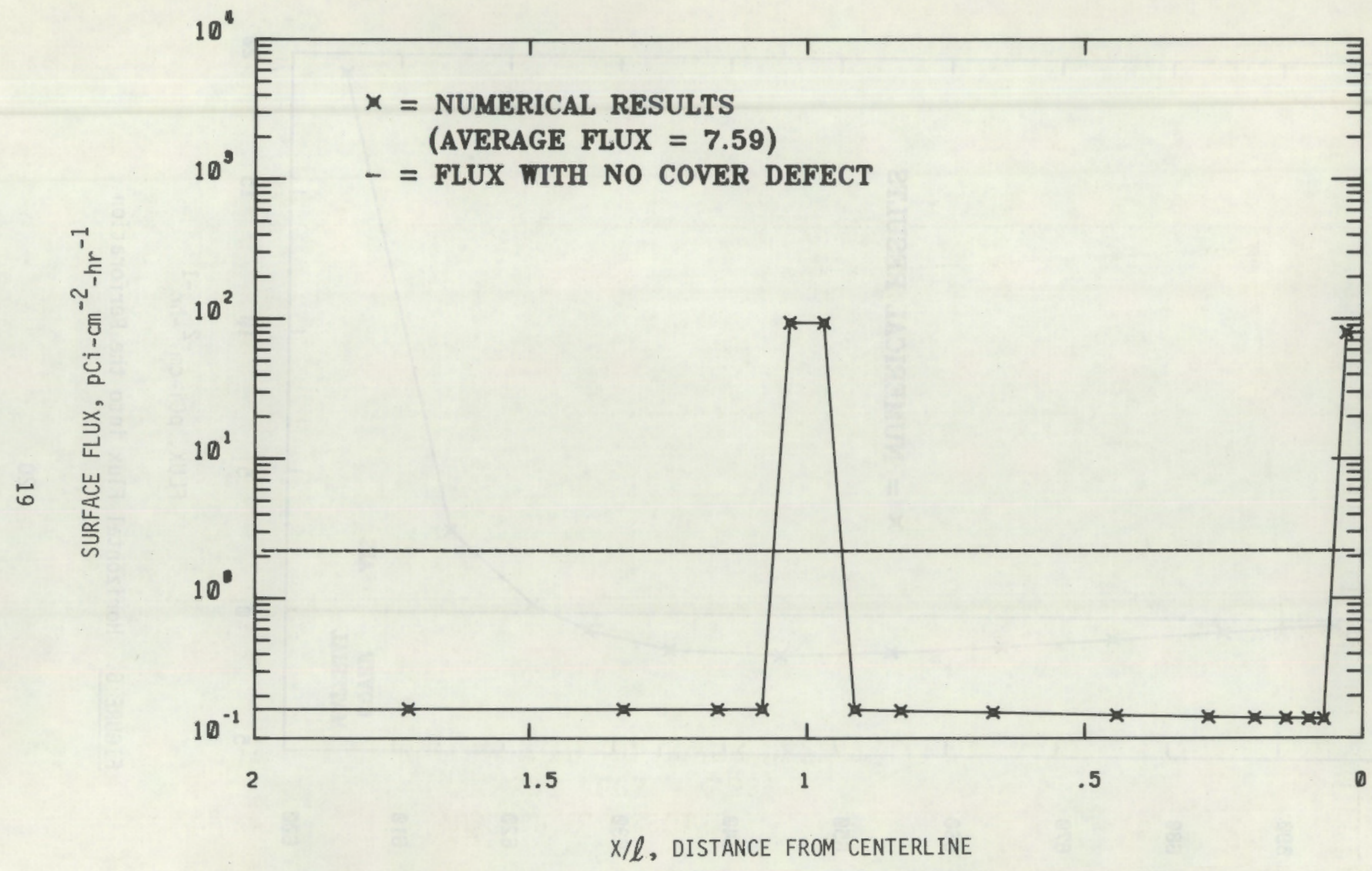

FIGURE 5d. Surface Flux, Small Defects Case 


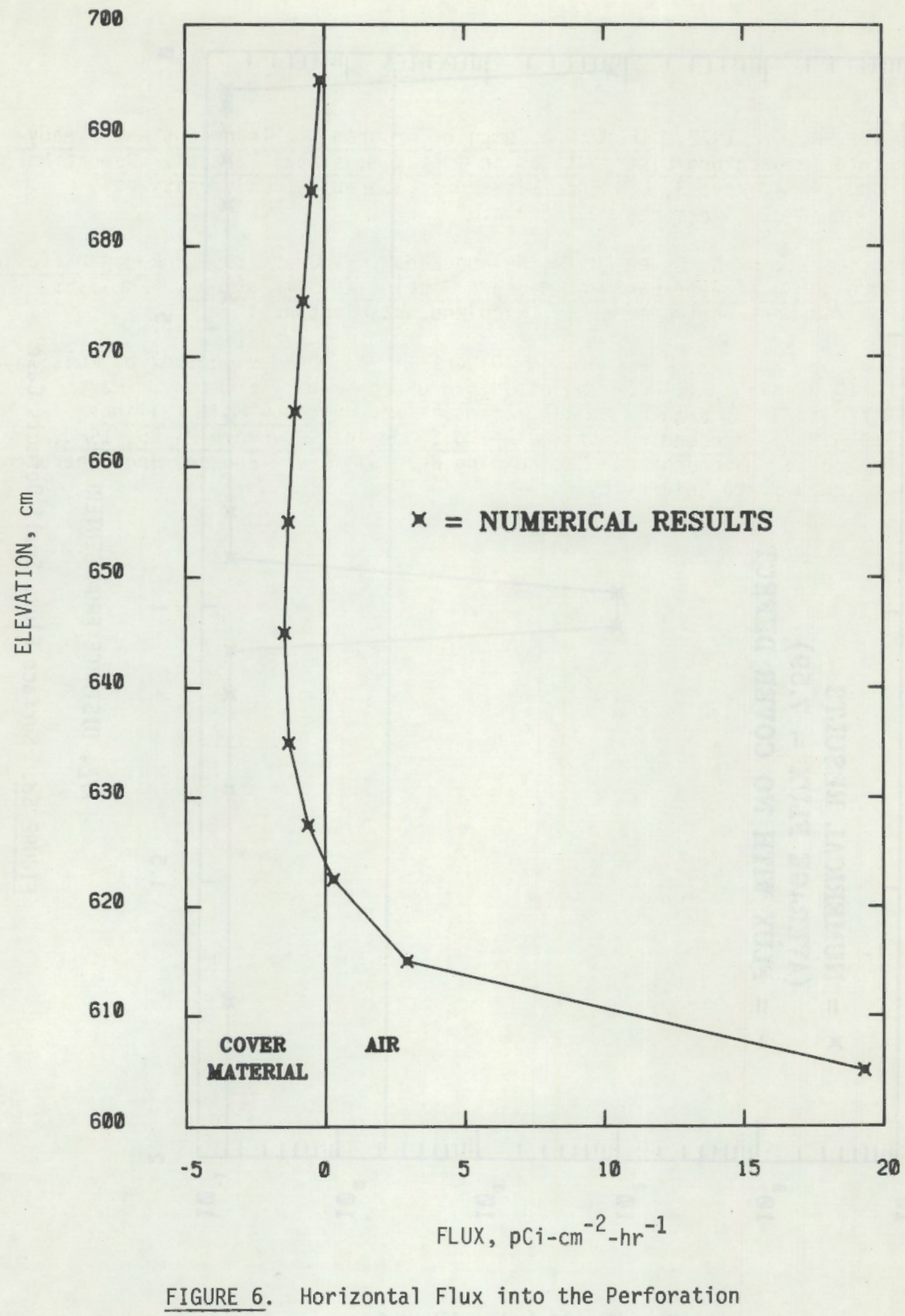




\section{REFERENCES}

Edwards, A. L. 1972. TRUMP: A Computer Program for Transient and SteadyState Temperature Distributions in Multidimensional Systems. Report No. UCRL-14754, Rev. 3, Lawrence Livermore Laboratory, University of California, Livermore, California.

Mayer, D. W., C. A. Oster, R. W. Neison and G. W. Gee. 1981. Radon Diffusion Through Multilayer Earthen Covers: Models and Simulations. PNL-3989, Pacific Northwest Laboratory, Richland, Washington.

Nelson, R. W., G. W. Gee and C. A. Oster. 1980. "Radon Control by Multilayer Earth Barriers, 1. Modeling of Moisture and Density Effects on Radon Diffusion from Uranium Mill Tailings." In: Uranium Mill Tailings Management, Proceedings of the Third Symposium, November 24-25, 1980, pp. 79-88. Geotechnical Engineering Program, Civil Engineering Department, Colorado State University. 



\section{DISTRIBUTION}

No. of

Copies

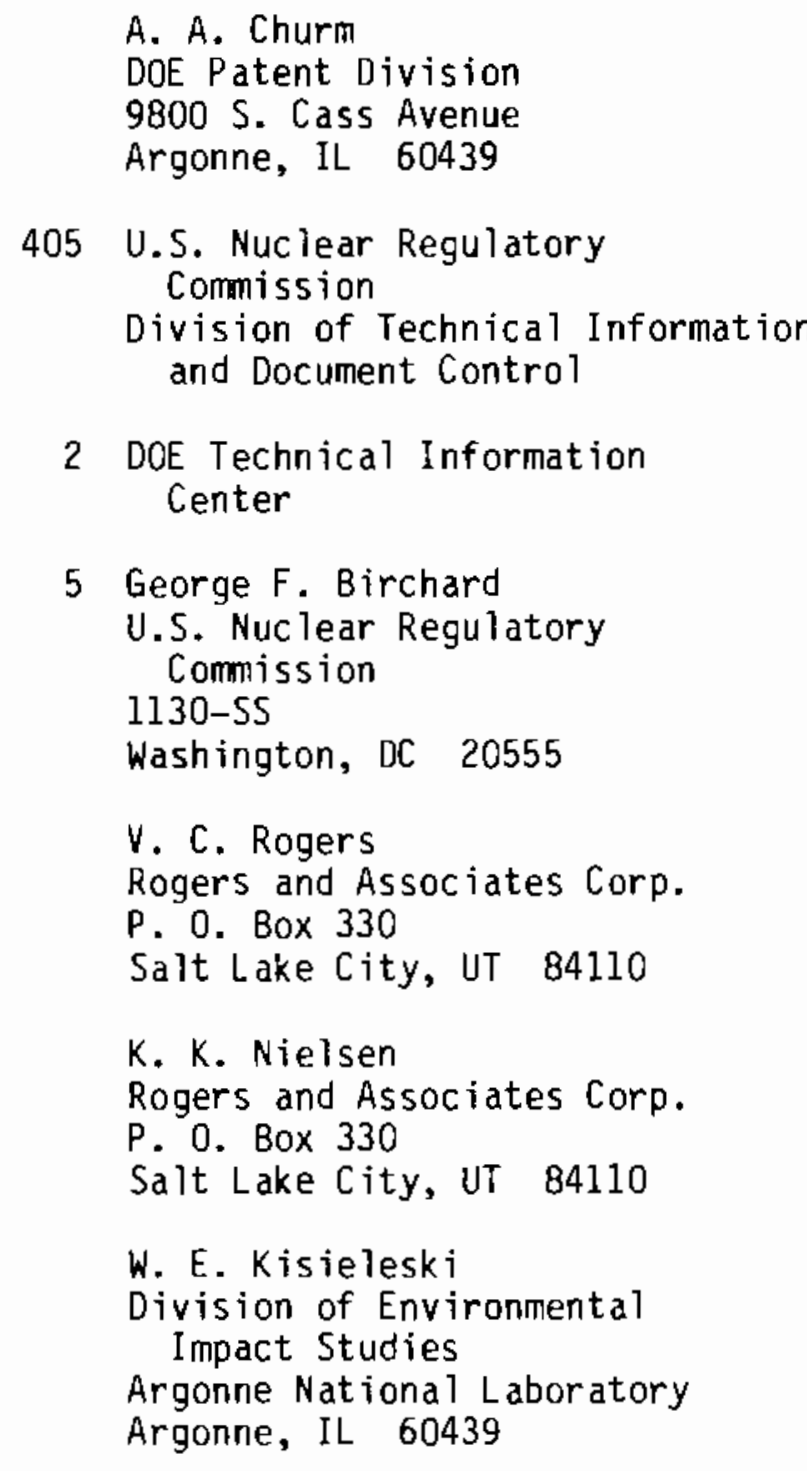

DOE Patent Division

9800 S. Cass Avenue

Argonne, IL 60439
Commission and Document Control

\section{Center}

J.S. Nuclear Regulatory

commission

$130-5 S$

V. C. Rogers

Rogers and Associates Corp.

. 0. Box 330

K. K. Nielsen

Rogers and Associates Corp. 330

W. E. Kisieleski

ivision of Environmental Impact Studies

Argonne, IL 60439
No. of

Copies

B. L. Cohen

Physics Department

University of Pittsburgh

Pittsburgh, PA 15260

ONSITE
50 Pacific Northwest Laboratory

S. M. Brown

D. B. Cear lock

W. I. Ender lin

W. D. Felix

J. S. Fruchter

G. W. Gee

J. A. Glissmeyer

J. N. Hartley

P. 0. Jackson

C. T. Kincaid

P. L. Koehmstadt

D. W. Mayer (10)

R. W. Nelson

J. M. Nielsen

R. W. Perkins

J. C. Schwendiman

W. B. Silker (B)

C. W. Thomas

V. W. Thomas

N. A. Wogman

D. A. Zimmerman (7)

Publishing Coordination BE (2)

Technical Information (5) 



\begin{tabular}{|c|c|c|c|}
\hline \multirow{3}{*}{\multicolumn{2}{|c|}{$\begin{array}{l}\text { NRC FORM } 335 \text { U.S. NUCLEAR AEGULATORY COMMISSION } \\
\text { BIBLIOGRAPHIC DATA SHEET } \\
\text { 4. TITLE AND SUETITLE (Add Volume No., if eppropriate) } \\
\text { Radon Diffusion Through Uranium Mill Tailings and } \\
\text { Cover Defects }\end{array}$}} & \multicolumn{2}{|c|}{$\begin{array}{l}\text { 1. REPOAT NUMBE A (Assigned br DOC) } \\
\text { NUREG/CR }-2457 \\
\text { PNL-4063 }\end{array}$} \\
\hline & & \multicolumn{2}{|l|}{ 2. (Leave blank) } \\
\hline & & \multicolumn{2}{|c|}{ 3. RECIPIENT'S ACCESSION NO. } \\
\hline \multicolumn{2}{|l|}{$\begin{array}{l}\text { 7. AUthohis } \\
\text { D.W. Mayer, D.A. Zimmerman }\end{array}$} & \multicolumn{2}{|c|}{\begin{tabular}{|c|c|} 
MONTH & YEAP \\
November & 1981 \\
\end{tabular}} \\
\hline \multirow{2}{*}{\multicolumn{2}{|c|}{$\begin{array}{l}\text { 9. PERFORMING ORGANIZATION NAME ANO MAILING ADDHESS (Include Zip Code) } \\
\text { Pacific Northwest Laboratory } \\
\text { Richland, WA } 99352\end{array}$}} & $\begin{array}{l}\text { MONTH } \\
\text { December }\end{array}$ & \begin{tabular}{l|l} 
SUED \\
TEAR \\
1981 \\
\end{tabular} \\
\hline & & \multicolumn{2}{|l|}{ 6. (Leave blank) } \\
\hline & & \multicolumn{2}{|l|}{ 8. (Leave biank) } \\
\hline \multirow{2}{*}{\multicolumn{2}{|c|}{$\begin{array}{l}\text { 12. SPONSORING ORGANIZATION NAME AND MAILING ADDRESS (Inciude Zio Code) } \\
\text { Division of Health, Siting and Waste Management } \\
\text { Office of Nuclear Regulatory Reseurch } \\
\text { U.S. Nuclear Regulatory Comission } \\
\text { Washington, DC } 20555\end{array}$}} & \multicolumn{2}{|c|}{ 10. PROJECT/TASK/WORK UNIT NO. } \\
\hline & & \multicolumn{2}{|l|}{$\begin{array}{l}\text { 11. CONTRACT NO. } \\
\text { FIN B2269 }\end{array}$} \\
\hline \multicolumn{4}{|c|}{ PERIOD COVEREO (Inclusive dares) } \\
\hline \multicolumn{2}{|l|}{ 15. SUPPLEMENTARY NOTES } & \multicolumn{2}{|l|}{ 14. (Leave ofank) } \\
\hline \multirow{2}{*}{\multicolumn{4}{|c|}{$\begin{array}{l}\text { Research was conducted at Pacific Northwest Laboratory to define the effects of } \\
\text { cover defects on the emission of radon gas from covered uranium mill tailings piles. } \\
\text { This report describes the results from the analysis of four geometrically simplified } \\
\text { cover defects. }\end{array}$}} \\
\hline & & & \\
\hline \multicolumn{4}{|l|}{ 17b. IDEN IFIERS/OPEN-EN DED TERMS } \\
\hline \multirow{2}{*}{$\begin{array}{l}\text { 18. AVAILABILITY STATEMENT } \\
\text { Unlimited }\end{array}$} & \multirow{2}{*}{\multicolumn{2}{|c|}{$\begin{array}{l}\text { 19. SECURITY CLASS (This redort } \\
\text { UnClass ified } \\
\text { 20. SECURITY CLASS thrs page! } \\
\text { Unclassified. }\end{array}$}} & 21 NO. OF PAGES \\
\hline & & & \begin{tabular}{|l} 
22. PAICE \\
S \\
\end{tabular} \\
\hline
\end{tabular}


